\title{
International Students' Learning Experience on Global Curriculum
}

\author{
Afzal Sayed Munna' ${ }^{(D)}$
}

\begin{abstract}
This article intended to analyze a current piece of international education practice in terms of its underlying values, culture, and philosophy, including the concept of international education (e.g., a curriculum model, an organizational or institutional structure, or a management style), and have particularly selected curriculum model to discuss. Furthermore, the article aims to explore and analyze international students' learning experience in the selected educational curriculums designed for them. Moreover, the article will assess how values, culture, and philosophy influence the learners' experience in the curriculums.
\end{abstract}

\section{Keywords}

education, students' experience, curriculum, skills development

\section{Introduction}

According to Sparapani et al. (2014),

\begin{abstract}
When thinking of a "global" curriculum, we think of widening one's perspective to look beyond ways in which one teaches (or the ways typical of the particular location/ cultural norms) and tries to understand alternative perspectives on curriculum as "what gets taught and how." (pp. 54-55)
\end{abstract}

The authors go on to say, "A 'global' curriculum is a concept that is symbiotic with a cosmopolitan community."

Currently, many students prefer working or learning away from their country of birth and, as a result, living in a globalized society (Alharahsheh \& Pius, 2019a, 2020a; Helmi \& Pius, 2018b). However, for them to be ready to access job opportunities, they are required to acquire subject-specific knowledge and skills to prepare them to be ready to compete in the globalized market or society (Alharahsheh \& Pius, 2019b). Also, the readiness also requires them to cooperate with their international peers (Kagan \& Stewart, 2004). In view of this, Kagan and Stewart (2004) argued that globalization is the driving demand for an internationally competent workforce with the proficient challenges from increasing diversity at the classrooms which alternatively require the necessity of a greater understanding of the global culture. Thus, globalization is ensuring that there are appropriate skills sets for the international-minded students and it becomes vital to ensure the education reform by focusing on the knowledge and skills important to students in the 21 st century.
International education has been in existence over a decade (Walker, 2002) and the concept of the global curriculum can better be traced, which is yet to acquire a single consistent meaning (Hayden \& Thompson, 1995). Although its meaning is closely linked with its rationale and the aim which is tentatively adopted for international education with a similar meaning to McKenzie's Pan-education, all educative efforts aim at fostering an international orientation in knowledge and attitudes and seek to build bridges between countries (McKenzie, 1998). While explaining the international mindedness, Hayden and Thompson (1995) explained developing the international understanding for global citizenship and the knowledge, attitudes, and skills of international mindedness and world mindedness.

The study focused on the learning experience and considered two distinct stakeholders, including Pearson and the International Students. The outcome of this research revealed that most of the international students find the initial stage of studying in the United Kingdom a cause of stress due to the language use and they also find the instructional language difficult, which ultimately affected their academic confidence and achievement. They also find the independent study hours confusing as they indicated that they have less guided learning hours in the United Kingdom

\footnotetext{
'University of Wales Trinity Saint David, London, UK

Corresponding Author:

Afzal Sayed Munna, Lecturer, Module Leader, and Programme Coordinator, University of Wales Trinity Saint David, London, Winchester House, I I Cranmer Road, Vassal, London SW9 6EJ, UK. Email: a.munna@uwtsd.ac.uk
} 
than at home. The focus group suggested that the British curriculum lacks international focus. The group recommended U.K institutions should deliver inclusive teaching and learning where internationalization informs the whole curriculum. Overall, these outcomes could be utilized to design more inclusive and international-friendly curriculum by broadening the support structures and across departments.

\section{Aim, Objectives, and Questions of the Research}

\section{Research Aim}

The study aimed to analyze international students' learning experience on global curriculum by reviewing the perception on Pearson business management program.

\section{Research Objectives}

The research objectives are to develop an understanding of the main themes associated with transition to U.K. higher education and to analyze student coursework (assignment) to develop an overview of perceived differences in teaching and learning.

\section{Research Questions}

Research Question 1: How do international students describe the differences between prior learning cultures and a new environment?

Research Question 2: How do they evaluate the effectiveness of the program they studying?

\section{Context}

It seems the higher education sector does not always hold the appropriate academic culture that fosters teaching and learning (Bell, 2016). For example, in United Kingdom, the academic culture is not the same for all educational providers as every educational institution's existing culture is shaped by diverse students' cultures from around the globe (Wenger, 2000). In view of this, most international students tend to find it difficult to adapt to the existing U.K. culture. Thus, diverse demographic and cultural differences, and differences in perceptions, affect global curriculum (Helmi et al., 2018c). Other factors, such as lack of awareness of the academic background of learners, age, race, learning expectations, and communication conventions, can also affect global curriculum (Helmi et al., 2018b).

In view of this, from own personal experience of teaching in AEP (Alternative Education Provider), designing a curriculum can be very difficult, especially when most of the learners are non-EU (European Union), Asians, and
Africans and when many of them have previous experience of time-constraint examination (written examination) at Higher Secondary Certificate (HSC) level. These students find it difficult to adapt to many curricula in the United Kingdom, such as that of Pearson BTEC (Business and Technology Education Council) HNC (higher national certificate)/HND (higher national diploma) higher education qualifications that require research-based assignments (mostly with about 3,000-3,500 words) using learning outcomes and pass criteria.

Indeed, this is a challenging experience for international students and confusing to measure the level of learning that has taken place. The article will explore further how Pearson global BTEC business program is viewed among those learners and assess whether the qualification is fit for purpose.

\section{Literature Review}

International education: Context. Kagan and Stewart (2004) defined international education as the means of varied activities among international/foreign students in various academic institutions. According to the authors, international studies refer to the international preparation of foreign students as a productive workforce, contributing citizens, and competent leaders in the interconnected global world. Kagan and Stewart suggested that international education should have the following elements to be called as international education:

1. knowledge of other culture, regions, and global and or international current issues/affairs;

2. skills adaptation considering the cross-cultural environment and communicating in various languages other than English; and

3. values of respect created by global equal views on others.

The similar study was carried from a review of the curriculum in the United Kingdom: internationalizing in a changing context by Hayden (2012). The author refers to the Oxfam approach, educational resources of which are widely used in the U.K. schools that also evidenced encouraging the students to develop knowledge, skills, and values needed to secure sustainability and fulfill their potential. Hayden (2012) also cross-referenced the work of Young (2008) and Department for Education and Skills (2004), which was more directed to the global agenda that considered curriculum as a means of preparing for a global competitive knowledge-based economy, and argued the work of Marshall (2011), where it was seen as economic dominance of U.K. global citizenship education policy.

Lauder et al. (2007), on their discussion of human capital from Drucker (1993), explained that it is the competition 
for ideas, knowledge, and skills that comes to define the new economy because it is no longer ownership of capital that generates wealth creation (Pius et al., 2020b). And subsequently, it is the educated labor that interprets the power shift, which depends on human and intellectual capital (Pius et al., 2020a), especially when reflecting on the increasing global economic competition (Leitch Review of Skills, 2006).

\section{Curriculum Development}

In general, understanding curriculum development is a broad and complex process. Angulo (1994) stated that curriculum can be defined in major two ways: a range of experiences directed to develop skills in the individuals and the series of training experiences that schools utilize to complete and perfect that development. Tyler (1949), on the contrary, explained that curriculum is all about the learning experience that meets and reach the institutional educational goals. Thus, the curriculum is designed according to a certain expectation of the institution that will deliver its goals instead of the needs of the students who will follow it in their learning.

Similarly, Arrieta (1990) defined the term curriculum development as the series of activities that the learners need to endeavor during their study to improve the abilities that would form them to decide upon issues in their life as adults. This view is also matching with other considerations (Alharahsheh, 2019b; Manian, 2020) as they indicated that curriculum development requires continuous engagement of different stakeholders with main focus on students.

In terms of Pearson, the company defines the curriculum development as a plan for providing sets of learning opportunities (Pearson Education, 1999). The company develops curriculum programs for students in schools and higher education alternative providers and also program country's readiness for the future. All nations, regardless of their stage of development, are busy modifying their school curriculum to adjust to a new and interdependent world economy. Those nations most effective in accurately anticipating the future and designing school programs that will serve their students well in that future will prosper. Those nations unable to redesign their curriculums for this new age will flounder or fail.

In view of this definition, Pearson understanding on the curriculum development and curriculum engagement on learnings is quite different where their term is more associated with a physical document such as textbooks, syllabus, teachers' guide, or learning package. This was reflected with the definition from Taba (1974) who stated the curriculum as a learning plan. This broadly includes the establishment of goals and objectives, selection and organization of content, implication of learning and teaching patterns, and a results evaluation program. On the contrary, Eisner (1979) claimed that there are three types of curriculum, which includes explicit curriculum, implicit curriculum, and null curriculum. According to Eisner, explicit curriculum is broadly used in the district and nationwide educational settings that include the learning outcomes, subjects to be taught at various level of education, academic content that should be taught within those subjects, the texts, the planning model, or any other required materials that support teachers to have students gain the knowledge and skills they are supposed to gain based on the standards or learning objectives that guide certain subject area Lave \& Wenger (1991).

On the contrary, the implicit curriculum is defined as teaching based on the pedagogy, which includes traditional education of culture, politics, religious education, and or social aspects and moral values Devine et al., (2002). This is also best described as the credit system for students who are enrolled in courses in different tracks within the school curriculum. A student who is in the highest track is given more credit for a grade than a student who receives the same credit in a lower track.

Finally, the null curriculum is defined to the subject or the content that is taught by mere teacher interest or specialization such as law, anthropology, the arts, communications, and economics.

Knowing the facets of the differential curriculum, this article would explore Pearson's curriculum and the impact of their curriculum on student's learnings, especially on the international students.

\section{Factors Affecting Curriculum Development}

Among many global factors, culture being the most influential factor while developing the curriculum. And it is worth saying that cultural and ethnicity mixture is a result of immigration and affected the U.K. education widely. This was also reflected in the study of Barbour and Barbour (2010), where they mentioned that the educational changes reflected on the nation's legislation and judicial modification. We as an educator deal with varied international students from multicultural countries with a wide range of diversity and ethnic groups. Due to this varied ethnic background of the learners (Helmi \& Pius, 2018a), we educators also vary in teaching and delivery (Alharahsheh, 2019a) for instance, using localized examples to make the concept of theory most understandable to the learners. Furthermore, educators need to consider key technology developments, enabling further innovation and creativity in learning and teaching (Manian, 2020).

This mixture of culture, ethnicity, and language plays a fundamental role within the Ecuadorian curriculum Dee, (2004). So much so that over the years, there has been an increasing interest led by Ecuadorian indigenous movements together with government forces to make changes within the Ecuadorian educational system so that the 
cultural rights of indigenous people are taken into account in educational matters Bicki (2008). On the contrary, political ideologies also affected the education system and also the curriculum development. Levin (2007) explained that the political ideologies emphasize on the education system by allocating the educational resources or might be introducing a particular education model or may promote and patronize particular education program for the country.

While considering the educational forces affecting the curriculum development, Tyler (2013) identified that the students themselves, the society, and the subject specialist also affected the development. There are other factors to consider which as well includes: school philosophies, learning psychology, and teachers as an educational agent.

In this regard, Dewey (1997) explained major two educational philosophies: one of which considers the traditional philosophy where the education emphasizes on the pattern of oppression and imposition where the students were to be obedient and passive receptors. With this system, the learners learn what was imposed to learn and also what benefits them in the society for themselves. This is quite common where teachers believe that the learners will learn the same amount of knowledge that they (teachers) taught and also what matters to them Dewar (2016). While following the experience of Pearson today's so-called learning outcomebased teaching, it is very much clear that the organization purposefully designed their curriculum to make the learners learn what they want them to learn. Alternatively, the progressive education system allows learners to grow with their intelligence as the philosophy supported the idea that the learning experience must be meaningful to the students as individuals Haidet \& Stein (2006). What students bring to class does matter and learning allows students to develop new skills from day to day. Finally, students are allowed to express themselves and fostered to become reasoning persons. Within this type of education, the ideology that teachers are not the only ones who bring knowledge to the class predominates (Dewey, 1997).

\section{Pearson Perspective of Curriculum and the Learning Experience}

Pearson claims that they design their global curriculum using the system thinking which is much more effective and creditworthy for the students, especially to the international students as it better prepares them to pursue university qualifications in future. Kauffman (1980) defined system thinking as "a collection of parts which interact with each other to function as a whole" (p. 4). On the contrary, Pearson defines a system as a set of components, which interact with each other to function as a whole to improve student learning. This definition implies a system perspective or the adoption of systems thinking.

\section{System Thinking}

System thinking can be seen as the reciprocal relationship that patterns the behavior that a student exhibits. However, there are several obstacles in the system thinking, among which the students find it difficult to break the personal frame of reference. These frames of reference could be available from the assumptions they possess among them about the level of study and also could be persuaded from the influence of peers. Simultaneously, the students tend to focus more on the objectives and lead activities: for instance, the classroom-based test, reading materials, and other lesson-related activities.

\section{System Coherence}

Educators believe that the achievement of the system thinking is a complex process and often requires the appropriate implementation of components to cohere or work together harmoniously. It would also be worthy to say this coherence is absolutely impossible to achieve but indeed enables the success of teachers and students. According to the National Research Council (2012), the literature on education policy often uses the term "coherence" interchangeably with "alignment." However, in this article, the author is using the term as the overall system alignment, which creates the learning diamond, including the curriculum, instruction, professional learning, assessment, and the teaching-learning ecosystem.

This article also would avoid discussing the involvement of other elements and only will focus on the curriculum. Considering the learning diagram for this article, the factor curriculum consists of the knowledge and skills in the subject areas that teachers are expected to teach and students are expected to learn. According to Pearson, the curriculum is communicated using the qualification specification and the sample context paper provided along with the specification. However, the theory of learning differs in the Pearson curriculum compared with other specific curriculum taught at university at the same level of study. For instance, at Level $4 \mathrm{HNC}$, a core unit for the students is to take Financial Accounting, whereas at the university, they prepare the students with the business plan required at the workplace. According to Black et al. (2011), a common approach for current curricula is a flatly organized "catalogue of desirable outcomes."

This is a true reflection on the curriculum at Pearson, as they believe the students are required to complete the learning outcomes that set on the unit specification rather than using their own judgment to the unit. There is very limited opportunity for the students to explore and facilitate their potential. In another note, the author found Pearson BTEC Business has many repetitive contents, which overlap the units, and also confuses learners to build their confidence. 
Table I. Reform of BTEC Since 2016.

\begin{tabular}{|c|c|c|}
\hline $\begin{array}{l}\text { Designed with educators, employers, and } \\
\text { professional groups to provide relevant } \\
\text { career-based learning }\end{array}$ & $\begin{array}{c}\text { Develops knowledge, skills and } \\
\text { understanding-theory and practical } \\
\text { application }\end{array}$ & $\begin{array}{l}\text { Modular design-progression at } \\
\text { learner's own speed from one } \\
\text { level to another }\end{array}$ \\
\hline $\begin{array}{l}\text { Min. } 40 \%-60 \% \text { mandatory content, } \\
\text { developed in consultation with over } \\
5,000 \text { stakeholders }\end{array}$ & $\begin{array}{l}\text { Features employability skills aligned to } \\
\text { those identified in the "Future of Skills } \\
\text { and Employment" report. }\end{array}$ & $\begin{array}{l}\text { Supports social mobility-access } \\
\text { and progression } \\
\text { Designed to be part of 16-19 }\end{array}$ \\
\hline $\begin{array}{l}\text { Designed to be "Applied Generals" } \\
\text { (primary progression in Higher }\end{array}$ & $\begin{array}{l}\text { Min. } 30 \%-40 \% \text { externally assessed (via a } \\
\text { mix of exams and tasks) }\end{array}$ & $\begin{array}{l}\text { curriculum, builds on Level } 2 \text {, } \\
\text { aids progression to Level } 4\end{array}$ \\
\hline $\begin{array}{l}\text { Education), and "Tech Levels" (primary } \\
\text { progression is to employment) }\end{array}$ & $\begin{array}{l}\text { Contains internal assessment to develop } \\
\text { and assess learners' practical skills }\end{array}$ & $\begin{array}{l}\text { Different sizes for different } \\
\text { learner profiles }\end{array}$ \\
\hline $\begin{array}{l}\text { Two sectors included in new Trailblazer } \\
\text { apprenticeships (Construction, } \\
\text { Engineering) }\end{array}$ & $\begin{array}{l}\text { Learners must obtain a minimum points } \\
\text { threshold across units to achieve the } \\
\text { qualification }\end{array}$ & $\begin{array}{l}\text { Supports and is largely funded } \\
\text { for learners aged 19-23 years }\end{array}$ \\
\hline
\end{tabular}

Source. Pearson Web (2018).

Note. BTEC $=$ Business and Technology Education Council.

\section{Method}

The article is written to explore the experience of international students' perceptions at London-based alternative education providers. The data were collected using the qualitative research approach, focus groups, and interview of the students using open-ended questions at undergraduate level (Alharahsheh \& Pius, 2020b; Saunders et al., 2009). The data were analyzed using Microsoft Excel to assess the international students' experiences in the classroom and how they have adapted to the challenges. The challenges were explored by looking at how previous studies of learners, cultural, and social factors prevent them from following the existing curriculum of the selected company. Also, the term international students in this report refers to any student who has prior learnings from the outside United Kingdom using a different national curriculum and system. Different ethical aspects and challenges were taken into consideration during the research process to ensure anonymity, confidentiality, power, and authority use. Therefore, the research has maintained very transparent communication based on informed consent from all participants and also ensured that participants were part of the process as volunteers with the full right to withdraw at any stage. Furthermore, the research outcomes will be shared with the involved participants, considering the value it can bring to their own academic and professional development (Saunders et al., 2009).

\section{Results and Analysis}

Pearson BTEC business and analysis. Pearson claims that their BTEC Business qualifications provide the access to highquality career-focused education and the BTEC specification was designed (which was launched in 2016) by discussing with more than 5,000 stakeholders, including the teachers, students, universities, and employers. According to their research, they found this specification was devised using the best quality research and deemed as the best education system in the world. Their claim can better be found from the analysis that the curriculum is designed keeping the essential BTEC character (which is learning by doing) and also by considering the externally assessed units (practical tasks and written test), which they believe would prepare a more career-focused learner, rather than just learning and acquiring knowledge. In another claim, they stated that their foundation of mandatory contents studied by the learner is what is exactly expected by the industry employers and also by the universities. According to Pearson, the new BTEC specifications were developed to meet the requirements set by Department for Education (DfE) to be counted as Applied General and Tech Level qualifications, for example, by including the required proportion of external assessment.

The new revised BTEC Business claims that the curriculum supports the learner's progression to higher education, career, and lifelong learning. The model developed using three basic elements can be found in Table 1 .

In response to the BTEC qualification and the learners' achievement, recent CBI survey of more than 28,000 businesses shows two thirds $(66 \%)$ fear that there will be a lack of sufficiently skilled people to fill roles and $81 \%$ say readiness for work is one of their three most important considerations when recruiting school and college leavers, so it is encouraging to see these students using BTECs to get the career-ready skills they need (CBI Pearson Education \& Skills Survey, 2018). Research undertaken by Pearson, Nesta, and Oxford Martin, including communication, teamwork, and application of technical knowledge, revealed the following:

- As with previous years, around 100,000 BTEC students confirmed places at university this Autumnapproximately one in four students starting at university will have a BTEC; 
- $90 \%$ of BTEC students are employed full-time after university graduation;

- $62 \%$ of large companies have recruited graduates with a BTEC; and

- BTEC qualifications support higher employment rates and higher wage returns.

This was also evidenced by the statement from Peter Jones CBE, Founder, Peter Jones Enterprise Academy, who said,

BTEC helps students get the skills that today's employers are looking for. BTEC courses give you real, hands-on experience in your chosen vocation. It's what I call "learning by doing" and means you'll genuinely be job-ready. They're designed with the help of teachers, employers and universities. This keeps the BTEC curriculum relevant to today's job market - it's the qualification you should have on your $\mathrm{CV}$.

On another statement, Rachna Udasi, winner, BTEC Student of the Year 2018, said (Table 2),

What motivated me to study a BTEC is the fact I can apply theory to real-world scenarios within a vocational context. It suits my learning style perfectly and has provided me with real skills that will be useful within employment. Developing my business skills within the BTEC course has also given me the confidence to set up my own social enterprise to help Ugandan children with dyslexia.

The above table indicates the most favorite subjects among the students for BTEC Nationals (2016), which was same as the BTEC National (2010). In the year 2016/2017, Pearson launched the first phase of the qualification, which was also delivered in 2017/2018. The table revealed that there is a substantial increase between the year 2016-2017 and 2017-2018; however, as these are the results of different cohorts, they cannot be compared directly, as BTEC allows flexibility on completion years. For instance, BTEC Nationals can be taken as a 1- or 2-year course and research shows that most of the learners at alternative providers have taken the courses in 2 years than in 1 year, and thus, 20172018 indicates more completion than 2016-2017.

\section{Southern Theory and the Impact on Creating Global Education}

This article was also influenced by the Southern Theory study, which reflects the understanding of inequalities and agency in the global economy knowledge. The theory revealed and criticized the cultural and intellectual domination by the global north. In this respect, the cultural struggle is itself a kind of decolonizing that replaces the knowledge system. It is hard to disbelieve the growing impact of colonial power imposed to the culture. Valentin Mudimbe (1998) in The Invention of Africa summarized
Table 2. Shows the Top Five Subject Sectors by the Students in $2016 / 2018$.

\begin{tabular}{lcc}
\hline & \multicolumn{2}{c}{ Completion } \\
\cline { 2 - 3 } Sector & $2016 / 2017$ & $2017 / 2018$ \\
\hline Business & 1,800 & 13,600 \\
Health and Social Care & 1,700 & 11,700 \\
Applied Science & 1,300 & 7,900 \\
Sport & 300 & 6,100 \\
Information Technology & 600 & 5,300 \\
\hline
\end{tabular}

Source. Pearson Web (2018).

what empire had to do-dominate space, integrate the local economy into global circuits, and reform the native's minds through religion and education. The British in India did the last, quite systematically setting up the largest of all colonial university system with a European-derived curriculum designed to train a local workforce of an empire. This could also be found from the new conceptual frameworks or rethinking familiar methods, to make them usable for the local social groups marginalized by the empire.

While analyzing the Pearson global business studies curriculum, the author found the influence from the Southern Theory. The question of practice by Connell (2018) referred decolonizing the curriculum by focusing and rewriting course plans, textbooks, and the online resources to give weight to the social experience to the students. This was found from the Pearson's recent development of the global curriculum, which included and involved more vocational and industry lead modules for the learners to best prepare for the future. She also suggested the knowledge formation, which is evident from the curriculum that embedded and practiced episteme, involving the labor through which knowledge is brought into being, sustained, developed, and communicated among the stakeholders.

Student experience analysis. The case study higher education provider recruits students from around the globe, with a higher rate from the EU nationals (46\%) of the overall students, accounting $45 \%$ for the business programs. At one point, this might seems inappropriate; however, the similar elements were identified and discussed on the international classroom and the "internationalisation" (Asteris, 2006; De Wit, 2002; Knight, 2006) of higher education, which evidences the importance of discussion of these issues. The challenges become acute, as there is a discrepancy on the relevant teaching and learning strategies in the light of international education and the increased number of recruitments.

On Quarter 2 (April 2020) (Figure 1), there were a series of data collected from the students to capture the view of their learning experience, which are presented here with 


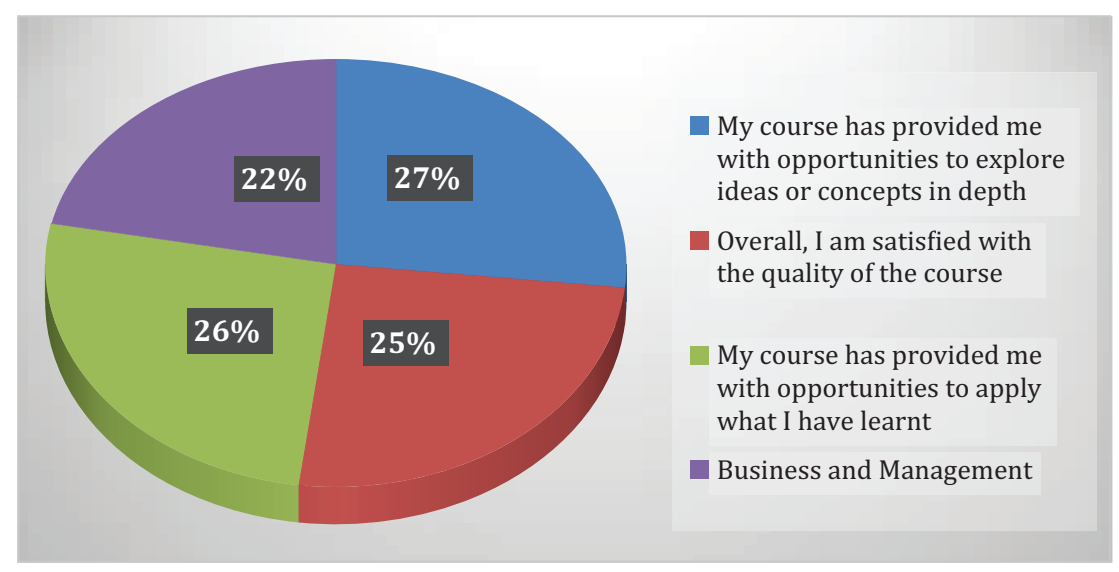

Figure I. Student satisfaction on the course.

Source. Data collected on from Quarter 2 (April 2020) period by the researcher.

support from the graphical presentation. The data were collected using various questions; however, the theme of those questions was related to the learning experience and their feedback on the Pearson Business Management qualifications at $\mathrm{HNC} / \mathrm{HND}$ level. There were a total of 115 respondents selected randomly from various cohort groups who were asked the same questions.

When asked about whether the course provided them with opportunities to explore ideas or concepts in depth, $89 \%$ responded agreed that the course has allowed them the opportunity to explore their ideas and concepts which they feel will be very useful in their future venture.

When asked whether the course provided them with opportunities to apply what they have learnt, $86 \%$ responded agreed that the course allowed them to build their selfesteem and boost their confidence to become an entrepreneur. Most of them believed that they will be able to utilize most of their learning in their professional career.

While asked about overall satisfaction, $84 \%$ of respondents replied that they are very happy and satisfied with the quality of the course. They also mentioned that the course structure (mostly the term design with the module delivery sequence) was satisfactory for them as it allowed them to build the pressure sequentially.

While reviewing the overall satisfaction from various departments, business management has received $73 \%$ on satisfaction rating compared with other programs taught in the same institute.

\section{Recruitment, Selection, and Students' Eligibility}

There are various criteria used to recruit international students and most of the selection criteria are predetermined by the United Kingdom Visa and Immigration (UKVI). The alternative education providers require complying with the required guidelines set and devised by them; however, some additional criteria are also being set by the institution itself. The common eligibility criteria are as follows:

- an unconditional offer of a place on a course with a licensed Tier 4 sponsor;

- enough money to support and pay for the coursethe amount will vary depending on individual circumstances;

- full-time leading to a qualification that is at least Level 6 on the Ofqual register;

- an overseas course of degree-level study that is equal to a U.K. higher education course and is being run by an overseas higher education institution;

- full-time, with at least $15 \mathrm{hr}$ per week of organized daytime study, leading to a qualification that is at least Level 3 on the Ofqual register;

- a recognized foundation program as a postgraduate doctor or dentist; and

- an English language course at Level B2 or above on the Common European Framework of Reference for Languages (source: https://www.gov.uk/tier-4-general-visa/eligibility).

Considering the above factors, the author found that international students face the biggest challenges mainly from the following three factors:

Language ability. Language is being the most important criterion for the selection process, and most international students find it difficult as the majority of them come from non-English-speaking countries. As stated above, the criterion is all students must have minimum English language requirement to provide the evidence of the test taken, including Test of English as a Foreign Language (TOEFL) 
or International English Language Testing System (IELTS). Although this test provides the proficiency of their English language ability however, they still face challenges, as they are unaware of the technical terminologies of the specialist subject area. These become acute when the curriculum requires self or independent study. For instance, a 15-credit unit requires Total Qualification Time (TQT) of $150 \mathrm{hr}$, among which $60 \mathrm{hr}$ only is Guided Learning and the remaining $90 \mathrm{hr}$ are student's independent study. However, to overcome the challenges, the institution provides additional English language lessons, which sometimes become an additional burden to the students and also require additional payment to the institution. This also can be viewed with a varied level of English proficiency as well. Some learners might be at a higher level of proficiency where they found the general academic English is too narrow for further development and thus lose interest and often become frustrated.

Social and cultural adjustment in the United Kingdom. According to Volet and Ang (1998), an institution requires demonstrating the duty of designing the learning that creates the environment to foster the students learning. The research and also the author experience of teaching international students for more than 8 years did not found that the lack of cultural and social knowledge affects the learning experience; instead, it is recommended that the lecturers should enforce on citing examples from the native cultures to make the lesson more interesting and close to the learners' heart. The focus group study revealed that the tutors should not assume that the learners should have the adequate social, cultural, and political knowledge of the host country (in this article, which is the United Kingdom); however, the group strongly felt that the education system and the assessment methods are far too different and challenging here in the United Kingdom compared with their native country. Thus, the group discussion, group presentation, peer discussion, and class contribution remained some of the critical challenges for the international students as the majority of the focus group members are from the country where the closed-book time-constraint examination is the only way to assess students' learning. However, the analysis contributed and reinforced with the comments from Jackson (2003) that to explore the necessity of building rapport is very crucial among the international students, which can only be achieved by allowing the social and cultural interaction for effective learning.

Study methods including curriculum. As stated in my earlier paragraph that assessment methods could be a taunting element with the international students, which was also agreed by De Vita (2001). In his piece of evidence, he also agreed that the methods and style of assessment differ among the countries and affect the performance of the students. While considering the group work as an example among the focus group, the author found group work become very intense due to the cultural diversity of groups that requires international students to acquire intercultural skills, which can be an onerous additional requirement in certain business subjects. Moreover, this result was varied among the groups as all the groups did not find the same level of stress, especially who seems to come from a collectivist culture.

The study revealed that as little as the submission of the written piece of evidence using the online learning platform (in this case, the Moodle linked with Turnitin) was a daunting and problematic experience for many learners who possess more cultural shock. It was a learning experience to the institutions that it should consider the isolation of the students from their native country who still require adjustment to address the isolation Sue (2010).

\section{Discussion: The Possibilities for Improvement}

It could be evident that international students find it difficult to cope with the challenges posed by the different learning environment (home vs. the United Kingdom). This might alternatively mean that the higher education providers require to make some induction planning for the new arrivals and also allow plenty of preparation and adjustment time. Also, it was evidenced by the students set for this research who had some prior knowledge of the United Kingdom stated that they expected some differences but did not expect the differences to be so broad. Students also comment that they encountered various learning challenges on the range of new learning tasks which they have to confront. This was also evidenced from Lea (2004) who stated that it is important to acknowledge that international students may have acculturation problems. Out of many, a key unanticipated challenge which students refer to is the variety of assessment methods in the United Kingdom. Most of the students stated that they were not familiar with the assessment's methods, especially the assignment and independent study. Without an analysis of assessment tasks, it is difficult to state whether these calls are fully necessary. However, students lack confidence in their approach to assessment. As was suggested in the literature review, there may not be clear lines of association with prior learning experiences. The findings also show how students find the interaction between language-level ability and their programs of study created intrapersonal tensions, especially students coming from different countries.

However, it was greatly agreed among the students that the explicit teaching of skills, both language and academic skills (often we call study skills, business and academic skills or academic and employability skills), could support the transitional stage of learning Dovidio et al. (2002). Higher education providers generally patronize more adjustments in terms of supporting independent learning. This may mean more directed learning for students or new 
methods of delivery through virtual learning environments (VLEs), especially teaching that requires online involved Harkavy \& Zuckerman (1999). As Lillyman and Bennett (2014) suggested, planning and targeted support may well improve the international student experience.

The study revealed and suggested the sample group of learners identified few areas for development, which clearly can improve the learning experience of the international students and are listed below. The author fully agreed with the comments from Byrne et al. (2002) that indicate that due to the present global changing learning environment, the students require more expert knowledge to be equipped to survive and thrive into the world of the competitive environment (Helmi et al., 2018a). The author believes that this not only brings the students close to the world of education but also would prepare them to be independent, active, and lifelong learners; the curriculum of the case study awarding organization (Pearson) also depicted the same motion for our future generations.

\section{Peer Mentoring}

Peer influence has a great impact on active learning and a peer is defined as the person and or individual who can impact someone with the required knowledge and experience that they already experienced from their previous learnings. The peer might already have had a similar situation, which they have overcome with the support of another peer and now acting to support the new learner with appropriate guidance. Hughes and Wisker (1998) also suggested the same thing, which the author revealed from this research and focus group experience. The findings from this research recommended that introducing a peer support group and language and cultural centers could improve the communicational barriers by international students. Considering the facts, the author has proposed to the institutions' management to introduce the cultural and language group among the HNC/HND learners for which the feedback from the students and management was very positive and encouraging. Following this recommendation, the institute has adopted and revised its vision statement and also introduced cultural events and language clubs to improve the learning experience that resulted in a higher number of accurate submission of written works and also equip the learners to demonstrate their ability to cope with the pressure better than before. In each class group, we now have a peer group that helps and assists the learners and also have a mentoring system in place that looks after the learners on their course completion and achievement of the passing grade on taught modules.

\section{Study Skills as a Noncredit Unit}

The institute introduced the study skills lesson which includes academic writing, report writing, referencing system, note-taking, and many more features that enable learners to prepare best for their writing work and also prepare them for the future. The institute designed and developed the study skills guidebook in association with the partner university to provide a better learning experience to its learners. It was identified from the research that the international students interact better among each other when they feel more comfortable with the language and the learning environment that creates the opportunity to interact most. The institute's study skills lesson includes $3 \mathrm{hr}$ compulsory attendance per week, which is graded but not credited from the awarding organization. However, Pearson appreciates the process and the approved the study skills guidebook as an example work done so far in line with the taught units. However, there is mixed experience from the learners who attended the lesson, which includes some barriers to the delivery, by the lecturers.

Among many findings from the focus group experience, the author found that the learners found the study skills lessons more interesting, promoting values, and surely eradicate the communication barriers among them. They found the lesson to be effective as it helped them to improve their academic writings and presentation skills. However, business students found this could be more interactive if the study skills link with their business units directly.

\section{Social and Extracurriculum Activities}

Hughes and Wisker (1998) stated that international students have a definite concern about the socialization, which was found from this research. This was found from the survey among the students that students liked the institution's new batch induction where they had the opportunity to know their classmates, unit tutors, and also the institute's management. They also liked the event that allowed them to have a question and answer session, which was open for any questions they have. The institute also has a team dedicated to arranging and organizing the educational trips within the United Kingdom and also with EU countries. Each term ends allow students to book trips they would like to join. These surely improved communication among the students and staffs and also reduced the tension of study stress. The most important achievement from these events was to overcome the cultural shocks among students. However, there was no pure indication on the Pearson qualification specification, which requires the institution to arrange such activities, but they appreciate these initiatives by the management in each annual review report.

\section{Effective Teaching, Learning, and Assessment}

The study is intended to address the teaching, learnings, assessment, and mostly the curriculum of Pearson, which 
were assessed from the learner's experience from various aspects. The findings of this research address how the teachings, learnings, and especially the curriculum develop the aspects for the learners to explore more in an inclusive way rather than traditional grade achievement. The study found that the growth of the international students coming to the United Kingdom for higher study requires the higher education providers adopt and provide more practical education elements that can prepare a learner better for the growing world. In this article, the author addressed the issues as the majority of the learners are coming from Far Eastern countries where English is the second language and examination is the only way of assessment of the student's learning. For instance, the focus group member from greater China exposed that they tend to be shy and less interactive with the lesson and with the tutor. The use of resource and note-taking methods is also diffident from others. In another example, the author found Chinese and Philippians are tending to use their dictionary, which they use to translate words from their own to English Wetzel (2013). Most students prefer their country examples into their lesson and prefer their own countries enterprises case while dealing with the classwork. This requires the tutors to prepare more and use varied teaching materials and educational resources. This was also recommended by Swisher and Schoorman (2001) with their comments that the class tutors require diverse cultural knowledge to make the real difference among the groups. Thus, the author suggests creating an inclusive and respecting the diversity of the learners provide an effective classroom and patronize a global culture in the lesson.

\section{Staff Development and CPD Program}

Staff development is the process to train and manage the tutors up to date with the industry requirements. The institute has a clearly defined Staff Continuous Professional Development (CPD) policy in practice, which allows all tutors teaching HNC/HND to be ready for the new curriculum and qualification specification as required by the industry. The institute allows all tutors to gain Higher Education Fellowship from Higher Education Academy, UK, and also requires all tutors to become a member for Society for Education and Training. The institute arranges every month's staff development meeting to organize the in-house training and CPD sessions for all tutors. It was identified that many of the stereotypes about international students will be reinforced and self-fulfilling. Biggs (1999) also highlighted the concept of assimilation as an approach to teaching international students. This was experienced from the focus group that expressed that the more active and industry-knowledgeable tutors help assist them more effectively and positively.

\section{Conclusion}

On November 2, 2018, Pearson report revealed that in the year 2018, around 430,000 qualifications have been taken by the students, which have been designed to high standards working with employers and include a proportion of rigorous external assessment Tiberius (1994). A new CBI survey of more than 28,000 businesses shows two thirds (66\%) fear that there will be a lack of sufficiently skilled people to fill roles and $81 \%$ say readiness for work is one of their three most important considerations when recruiting school and college leavers, so it is encouraging to see these students using BTECs to get the career-ready skills they need (Pearson.com, 2018). The study here addressed the learning experience of international students studying at one of London's alternative education providers. The findings of the research indicate that the newly designed global curriculum has a great impact on student's learnings, which make them best prepared for the industry. It also indicates some common and primary duties by the alternative providers to improve and foster the learning experiences by the international students that are easily achievable and can create an inclusive learning environment. The study indeed ignored the analysis and comparison among the providers, which could provide better comparative analysis for the future.

\section{Declaration of Conflicting Interests}

The author(s) declared no potential conflicts of interest with respect to the research, authorship, and/or publication of this article.

\section{Funding}

The author(s) received no financial support for the research, authorship, and/or publication of this article.

\section{ORCID iD}

Afzal Sayed Munna iD https://orcid.org/0000-0001-7302-8037

\section{References}

Alharahsheh, H. (2019a). Descriptive writing style: The use of critical incidents within Higher Education Settings for further professional development. South Asian Research Journal of Arts, Language and Literature, 2(1), 53-55.

Alharahsheh, H. (2019b). Employability skills development through assessment in higher education: Students' voices on reflective assessments. University of Greenwich.

Alharahsheh, H., \& Pius, A. (2019a). Creating business value and competitive advantage through glocalization. In V. Nadda, S. Bilan, M. Azam, \& D. Mulindwa (Eds.), Neoliberalism in the tourism and hospitality sector (pp. 83-98). IGI Global.

Alharahsheh, H., \& Pius, A. (2019b). Employability skills development through assessment in higher education: Students' voices on reflective assessments. Global Academic Journal of Economics and Business, 1(2), 36-42. 
Alharahsheh, H., \& Pius, A. (2020a). Exploration of employability skills in business management studies within higher education levels. International Journal of Sustainable Economies Management, 9(1), 52-69.

Alharahsheh, H., \& Pius, A. (2020b). A review of key paradigms: Positivism VS interpretivism. Global Academic Journal of Humanities and Social Sciences, 2(3), 39-43.

Angulo, J. F. (1994). Teoría y desarrollo del curriculum. Málaga: Ediciones Aljibe.

Arrieta, J. (1990). The evolution in Spain of the theory and practice of curriculum, Journal of Curriculum Studies, 22.

Asteris, M. (2006). British universities: The "coal exporters" of the 21 st century. Journal of Studies in International Education, 10(3), 224-240.

Barbour, C. H., \& Barbour, N. H. (2010). Families, schools, and communities: Building partnerships for educating children. Pearson.

Bell, J. (2016). How can lecturers and students in higher education improve their intercultural awareness, and in the process create a more inclusive international teaching and learning environment? Equality and diversity in learning and teaching in higher education. Higher Education Academy.

Bicki, A. (2008, June). An observation of nonverbal immediacy behaviours of native and non-native lecturers. Journal of Social Sciences, 5(1). http://www.academia.edu/4922470/ Teacher non-verbal immediacy behaviours

Biggs, J. (1999). Teaching for quality learning at university. SRHE \& Open University Press.

Black, P., Wilson, M., \& Yao, S.-Y. (2011). Road maps for learning: A guide to the navigation of learning progressions. Measurement: Interdisciplinary Research and Perspectives, $9(2-3), 71-123$.

Byrne, M., Flood, B., \& Willis, P. (2002). Approaches to learning of European Business Students. Journal of Further and Higher Education, 26(1), 19-28.

CBI Pearson Education \& Skills Survey. (2018, November). Education for the modern world. http://cdn.roxhillmedia. $\mathrm{com} /$ production/email/attachment/700001_710000/CBI\%20 Education\%20and\%20Skills\%20Annual\%20Report\%20 2018.pdf

Connell, R. (2018). Decolonizing sociology. Contemporary Sociology, 47(4), 399-407.

Dee, T. S. (2004). The race connection: Are teachers more effective with students who share their ethnicity? Education Next, 4(2), 52-59. http://educationnext.org/the-race-connection /\#comments

Department for Education and Skills. (2004). Putting the world into world class education. DfES.

Devine, P. G., Plant, E. A., Amodio, D. M., Harmon-Jones, E., \& Vance, S. L. (2002). The regulation of explicit and implicit race bias: The role of motivations to respond without prejudice. Journal of Personality and Social Psychology, 82(5), 835848. http://www.uky.edu/AS/PoliSci/Peffley/pdf/Sniderman /Devine Plant 2002 The $\% 20$ Regulation $\% 20$ of $\% 20$ Explicit\%20and\%20Implicit\%20Race\%20Bias JPSP.pdf

De Vita, G. (2001). The use of group work in large and diverse business management classes: Some critical issues. International Journal of Management Education, 1, 27-35.
Dewar, G. (2016). Student-teacher relationships: The overlooked ingredient for success. Parenting Science. https://www.par entingscience.com/student-teacher-relationships.html

Dewey, J. (1997). Experience \& education. Touchstone.

De Wit. (2002). Internationalization of higher education in the United States of America and Europe: A historical, comparative, and conceptual analysis. Greenwood Press.

Dovidio, J. F., Kawakami, K., \& Gaertner, S. L. (2002). Implicit and explicit prejudice and interracial interaction. Journal of Personality and Social Psychology, 82(1), 62-68. https:// static1.squarespace.com/static/525d656ce4b0be2ae63502ed/ $\mathrm{t} / 527 \mathrm{a} 8 \mathrm{~d} 70 \mathrm{e} 4 \mathrm{~b} 08095 \mathrm{ec} 9 \mathrm{bade} 2 / 1383763312390 /$ Dovidio + Kawakami+Gaertner+2002.pdf

Drucker, P. F. (1993). Management: Tasks, responsibilities, practices. Harper Collin.

Eisner, E. W. (1979). The educational imagination: On the design and evaluation of school programs. Macmillan.

Haidet, P., \& Stein, H. F. (2006). The role of the student-teacher relationship in the formation of Physicians. Journal of General Internal Medicine, 21, S16-S20.

Harkavy, I. \& Zuckerman, H. (1999). Higher education: Handbook of theory and research (Vol. 31, M. B. Paulsen, Ed.). Springer.

Hayden, M. C., \& Thompson, J. J. (1995). Perceptions of international education: A preliminary study. International Review of Education, 41(5), 389-404.

Hayden, M. (2013). A review of curriculum in the UK: Internationalising in a changing context. The Curriculum Journal, 24(1), 8-26.

Helmi, H., \& Pius, A. (2018a). Case study of critical incident in teaching within higher education. Scholars International Journal of Linguistics and Literature, 1(2), 55-57.

Helmi, H., \& Pius, A. (2018b). A review of international students' attraction and recruitment strategies: Learning from UK top universities. Scholars Journal of Economics, Business and Management, 5(8), 779-785.

Helmi, H., Pius, A., \& Guenane, I. (2018a). Enhancing international students' recruitment within higher education: Focus on the Middle East region. International Journal of Management and Humanities, 3(6), 1-5.

Helmi, H., Pius, A., \& Guenane, I. (2018b). The importance of research informed teaching in higher education: A case study of London College of Contemporary Arts (LCCA). Journal of Advances in Education and Philosophy, 2(3), 89-94.

Helmi, H., Pius, A., \& Guenane, I. (2018c). UK Higher Education Institutions role in students' skills development for employment. Journal of Advances in Education and Philosophy, 2(3), 85-88.

Hughes, S., \& Wisker, G. (1998). Improving the teaching and learning experiences of overseas students. In C. Rust (Ed.), Improving student learning: Improving students as learners. Oxford Centre for Staff \& Learning Development.

Jackson, P. (2003). Ten challenges for introducing Web-supported learning to overseas students in the social sciences. Active Learning in Higher Education, 4(1), 87-106.

Kagan, S. L., \& Stewart, V. (2004). Putting the world into worldclass education: Introduction. Phi Delta Kappan Magazine, 86(3), 195-196. 
Kauffman, D. L. (1980). Systems one: An introduction to systems thinking. Future Systems.

Knight, J. (2006). Higher education in turmoil: The changing world of internationalization. Sense Publishers.

Lauder, H., Brown, P., \& Ashton, D. (2007). Education, globalisation and the future of the knowledge economy. European Educational Research Journal, 7(2), 131-156.

Lave, J., \& Wenger, E. (1991). Situated learning: Legitimate peripheral participation. Cambridge University Press.

Lea, M. (2004). Academic literacies: A pedagogy for course design. Studies in Higher Education, 29(6), 740-755.

Leitch Review of Skills. (2006). Prosperity for all in the global economy-World-class skills [Final report]. Her Majesty's Stationery Office.

Levin, B. (2007). Curriculum policy and the politics of what should be learned in schools. In M. Connelly, M. F. He, \& J. A. Phillion (Eds.), Handbook of curriculum and instruction (pp. 7-24). SAGE.

Lillyman, S., \& Bennett, C. (2014). Providing a positive learning experience for international students studying at UK universities: A literature review. Journal of Research in International Education, 13(1), 63-75.

Manian, S. (2020). Designing e-learning environments in higher education to match technological trends. In B. Adekunle, H. Alharahsheh, \& A. Pius (Eds.), Trends and issues in international planning for businesses (pp. 152-166). IGI Global.

Marshall, H. (2011). Education for global citizenship: Reflecting upon the instrumentalist agendas at play. In R. Bates (Ed.), Schooling internationally: Globalisation, internationalisation and the future for international schools (pp. 182-99). Routledge.

McKenzie, E. M. (1998). Going, going, gone ... global! In M. C. Hayden \& J. J. Thompson (Eds.), International education: Principles and practice (pp. 242-252). Kogan Page.

Mudimbe, V. (1998). The invention of Africa: Gnosis, philosophy and the order of knowledge, indianapolis. Indiana University Press.

National Research Council. (2012). A framework for K-12 science education: Practices, crosscutting concepts, and core ideas. National Academies Press.

Pearson Education. (1999). Curriculum development in a global age. https://www.pearsonhighered.com/assets/samplechapter/0/1/3/3/0133833569.pdf

Pearson Web. (2018). https://www.pearson.com/uk/about-us/ news-and-policy/news/2018/11/2018-btec-results-datashows-more-students-acquiring-the-skills-required-to-meetthe-changing-needs-of-employers.html

Pearson. com (2018). https://www.pearson.com/news-and-research/ announcements/2019/02/pearson-2018-results.html
Pius, A., Alharahsheh, H., \& Sanyang, S. (2020a). Approaches and practices in strategic human resources management. In B. Adekunle, H. Alharahsheh, \& A. Pius (Eds.), Trends and issues in international planning for businesses (pp. 42-66). IGI Global.

Pius, A., Alharahsheh, H., \& Sanyang, S. (2020b). Trends and issues in strategic human resources management. In B. Adekunle, H. Alharahsheh, \& A. Pius (Eds.), Trends and issues in international planning for businesses (pp. 17-41). IGI Global.

Saunders, M., Lewis, P., \& Thornhill, A. (2009). Research methods for business students (5th ed.). Pearson Education.

Sparapani, E. F., Perez, D. C., Gould, J., Hillman, S., \& Clark, L. (2014). A global curriculum? Understanding teaching and learning in the United States, Taiwan, India, and Mexico. SAGE Open. Advance online publication. https://doi .org/10.1177/2158244014536406

Sue, D. W. (2010). Microaggressions in everyday life: Race, gender, and sexual orientation. Wiley.

Swisher, K., \& Schoorman, D. (2001). Learning styles: Implications for teachers. In C. F. Diaz (Ed.), Multicultural education for the 21st century (pp. 55-70). Addison Wesley Longman.

Taba, H. (1974). Curriculum development: Theory and practice. Harcourt, Brace \& World.

Tiberius, R. G. (1994). The why of teacher/student relationships. Essays on teaching excellence. The Professional \& Organizational Development Network in Higher Education. http://podnetwork.org/content/uploads/V5-N8-Tiberius.pdf

Tyler, R. W. (1949). Basic principles of curriculum and instruction. University of Chicago Press.

Tyler, R. W. (2013). Basic principles of curriculum and instruction. The University of Chicago Press.

Volet, S. E., \& Ang, G. (1998). Culturally mixed groups on international campuses: An opportunity for intercultural learning. Higher Education Research and Development, 17(1), $5-23$.

Walker, G. (2002). To educate the nations: Reflections on an international education. John Catt Educational.

Wenger, E. (2000). Communities of practice and social learning systems. Organization, 7(2), 225-246.

Wetzel, J. (2013, August 27). Vanderbilt education expert: Unintentional discrimination illegal, unacceptable. Vanderbilt News. http://news.vanderbilt.edu/2013/08/vanderbilt-expertdiscrimination-illegal/

Young, M. (2008). Bringing knowledge back in: From social constructivism to social realism in the sociology of education. Routledge. 